\title{
Cost-effectiveness analysis of arthroscopic surgery versus open surgery in rotator cuff repair
}

\author{
Mehmet Akif AKCAL ${ }^{1}$ (D), Nazife OZTURK² (D), Ferda ISIKCELIK ${ }^{3}$ (D) Ismail AGIRBAS $^{3}$ (D) \\ ${ }^{1}$ Orthopedics and Traumatology Clinic, Antalya Atatürk State Hospital, Antalya, Turkey. \\ ${ }^{2}$ Antalya Province Health Directorate, Antalya, Turkey. \\ ${ }^{3}$ Department of Health Management, Faculty of Health Sciences, Ankara University, Ankara, Turkey.
}

\author{
Corresponding Author: Nazife OZTURK \\ E-mail: nazife_sahan@yahoo.com
}

Submitted: 16.09.2020 Accepted: 23.11.2020

\section{ABSTRACT}

Objective: This study aimed to compare the open and arthroscopic rotator cuff tear treatment methods in terms of cost-effectiveness. Materials and Methods: This study includes a prospective method of a total of 104 patients, 52 with open surgery and 52 with arthroscopic surgery, in the treatment of rotator cuff tears. Cost calculations of the treatment methods were obtained from patient invoices. Oxford Shoulder Score and Short Form-36 Health Survey Questionnaire were used for effectiveness calculations. The costeffectiveness comparison was conducted using the Incremental Cost Effectiveness Ratio (ICER) assessment. The difference between costs of open and arthroscopic surgery was analyzed using the SPSS 23.0 package program, with Mann-Whitney U test.

Results: The average cost per patient was 4,838.7 Turkish Liras (TL) (866.22 USD) in open surgery and 5,770.33 TL (1,033.00 USD) according to the exchange rate at the time of writing, in arthroscopic surgery. Oxford Shoulder Score was 21.15 in open surgery and 20.83 in arthroscopic surgery. Short Form-36 Health Survey Questionnaire score was 61.92 in open surgery and 63.17 in arthroscopic surgery. The ICER calculated according to the Oxford Shoulder Score was - 2,912.37 TL (521,37 USD), while the ICER calculated according to the General Health Perception sub-scale of Short Form-36 was 745.57 TL (133,47 USD). In addition, statistical significant difference was found between the surgery, medication, medical and surgical materials, hospitalization and average cost of those treated with open surgery and those treated with arthroscopic surgery $(\mathrm{p}<0.05)$.

Conclusion: There was no statistically significant difference between the efficacy scores of the treatment groups. However, there was statistically significant difference between costs of the treatment groups.

Keywords: Rotator cuff injuries, Rotator cuff repair, Cost-effectiveness

\section{INTRODUCTION}

The largest part of the shoulder joint function is performed by the rotator cuff [1]. The rotator cuff muscles and the extrinsic shoulder muscles are located around the shoulder joint to perform a specific rotational motion [2]. The tear of the rotator cuff is the most common musculoskeletal injury to the shoulder [3] and is the common cause of shoulder pain and shoulder disability [4]. Shoulder pain (16\%), was shown as the third most common pain in the musculoskeletal system after knee pain (19\%) and low back pain (23\%) [5,6].

Pain in shoulders causes a significant socioeconomic burden; disability of the shoulder can impair the ability to work or perform household tasks and can result in time off work [5]. It is estimated that there are 4.5 million outpatient visits in the United States of America (USA) each year for shoulder pain, and these are usually associated with rotator cuff pathologies
[7]. According to the Ministry of Health $(\mathrm{MoH})$ in Turkey in "First 100 Hospitals in All Branches Report (2017)", the number of patients admitted to the Orthopedics and Traumatology units constitutes about $5 \%$ of all patients [8]. In rotator cuff tears, the ability of the shoulder joint to function as well as the ability to perform basic activities are impaired. Rotator cuff tear also causes significant labor shortages, loss of movement, reduced quality of life, and increased health care costs $[9,10]$.

Rotator cuff tear is characterized by shoulder pain, and it is a cause of pain and disability among adults. Conservative and surgical treatment options are available for the treatment of rotator cuff diseases. The importance of pain in treatment decision-making has yet to be determined, particularly since psychosocial factors have been demonstrated to play a more important role in patient-reported pain and function than

How to cite this article: Akcal MA, Ozturk N, Isikcelik F, Agirbas I. Cost-effectiveness analysis of arthroscopic surgery versus open surgery in rotator cuff repair. Marmara Med J 2021;34:(1):66-71. doi: 10.5472/marumj.869051 marumj.869051 
tear severity $[11,12]$. The conservative method includes combinations of rest, exercise, physiotherapy and painkillers $[13,14]$. Without repair, the rotator cuff has limited capacity to heal; conservative treatment often yields a satisfactory outcome, however the main disadvantages of a non-surgical approach are tear progression, ongoing pain, and deterioration in function over time [15,12].

The heal of the rotator cuff is associated with an improvement in function. The optimal treatment option for symptomatic rotator cuff tears is unknown and for many years there has been conflicting evidence as to which is the most effective method. Arthroscopic surgery causes less damage to surrounding soft tissues such as the deltoid, and has the theoretical advantage of causing less postoperative pain while permitting earlier mobilization [16]. Surgical methods include arthroscopic or open surgical procedures [17]. The use of these methods varies depending on the type of tear and the condition of the patient and tissue [18]. The costs and the effects on the quality of life of patients of these surgical treatment methods, which can be applied to similar patient groups, are different. Rotator cuff repair is a very costly operation [19]. As with all health services, increasing costs in rotator cuff repair is a worldwide phenomenon. Therefore, it is becoming more important to reduce healthcare delivery costs [20]. The dissimilar costs of the treatment methods used in the treatment of the same disease, as well as the different effects on the quality of life of the patients, necessitates the comparison between alternative methods. Given the increasing costs and scarce resources, there is a need to make comparisons between different rotator cuff tear treatment methods, which is itone of the major health problems. Rotator cuff surgery is one of the most widely performed orthopedic surgical procedures, and surgery volume is on the rise [21].

In this study, we aimed to compare the open and arthroscopic rotator cuff tear treatment methods in terms of cost-effectiveness analysis. We hypothesized that arthroscopic rotator cuff tear surgery would be more cost-effective than open surgery.

\section{MATERIALS and METHOD}

In this study, we aimed to compare open and arthroscopic rotator cuff tear treatment methods with cost-effectiveness analysis. The study was approved by the Ethical Committee of the Faculty of Health Sciences, Ankara University (approval number: 56786525-050.04.04/7564). This study utilizes the prospective research method, it has been conducted between September 2018 and April 2019. One hundred and four patients who met the inclusion criteria and each group who underwent open and arthroscopic surgery were included in the study. The surgeons used their usual preferred method of repair. Inclusion criteria were (1) the patients who had shoulder pain between 4 and 6 months, (2) had a tear $\leq 3 \mathrm{~cm}$, (3) the tear had been confirmed with magnetic resonance imaging (MRI) and ultrasound findings. Exclusion criteria were (1) had massive tears, (2) previous surgical procedure on either shoulder, (3) preceding trauma. Patients operated on with the arthroscopic method were treated with tendon bone fixation. Informed consent was obtained from each patient prior to surgery.

In this study conducted from the perspective of the public funded health care system cost data were obtained from hospital information system. The average cost of open and arthroscopic surgical treatment methods was calculated based on the invoiced amounts for each group of patients. Besides, the invoice amounts were classified under the headings of the operation, medicaments, medical and surgical materials, medical imaging and hospitalization expenses and their share in total expenses was calculated.

The Oxford Shoulder Score and Short Form 36 Health Survey Questionnaire scoring systems were used to measure the effectiveness criteria in the study. The Oxford Shoulder Score commonly used for quality of life in orthopedics was applied. The Oxford Shoulder Score has been shown to correlate well with the Short Form 36 ( $r>0.5)$ [19]. The Oxford Shoulder Score is a scale developed to evaluate the functional status of patients with certain shoulder problems [22]. It consists of 12 questions, each with five answer options, where 1 represents the best and 5 the worst [23]. The total score of the 12 questions gives the Oxford Shoulder Score for each individual. Scores from each question are combined to achieve a single score on a scale where 48 represents the best and 0 represents the worst $[24,25,19]$. This indicates severe shoulder arthritis at score 0 to 19 , moderate to severe shoulder arthritis at score 20 to 29 , mild to moderate shoulder arthritis at score 30 to 39 and satisfactory joint function at score 40 to 48 [25].

The Short Form 36 Health Survey Questionnaire consists of 36 questions measuring health status in three categories: functional ability, welfare and general health. The health status of the person is measured in eight sub-parameters. Functional ability category consists of sub-parameters of physical function, social function, limitation due to physical problems, limitation due to emotional problems; welfare category consists of subparameters of emotional well-being, energy-fatigue, body pain and general health category consists of sub-parameter of general health perception. Each item response is on a 6-point scale (from "always" to "never"). The total score is calculated by reversing the answers into two items (third and fifth), adding the scores and converting the raw scores to a scale ranging from 0 to 100 [20]. The scale gives a separate total score for each subscale instead of a single total score. A higher score means better health $[25,26]$.

\section{Data Analysis}

The invoices of patients treated between September 2018 and April 2019 were examined and the costs of alternative treatment methods for the reimbursement institution were calculated. Reduction was not performed because the data were collected prospectively and did not cover a short time.

The aim of surgical treatment is to minimize deterioration in shoulder function and this significantly increases the quality of life of the patient. After surgery, patients are taken under a rehabilitation programme for the first year $[15,27,12]$. In this 
study for the comparison of the effect of treatment methods, Oxford Shoulder Score and Short Form 36 measurement tools were applied to both groups the $16^{\text {th }}$ week after surgery.

\section{Statistical Analysis}

To determine whether there is a univariate end value in the data set, $\mathrm{z}$ values outside the range of -3 to +3 were examined. To investigate the univariate normality, descriptive statistics of the scores obtained from Oxford Shoulder Score and Short Form 36 scales and of the cost were calculated and histograms were drawn for their distribution. From the descriptive statistics of these distributions, it is necessary to provide the univariate normality assumption considering the mean, mode and median and skewness and kurtosis coefficients. As a result, it was seen that the univariate normality assumption was not provided by considering the mean, mode and median and skewness and kurtosis coefficients. Also, the normality hypothesis was tested by the Shapiro-Wilk and Kolmogorov-Smirnov tests. In the selection of significance tests, whether the distributions were normal or not was taken into consideration. According to these results, the Mann-Whitney $U$ test was used to analyze whether the mean scores of the two non-normally distributed groups were different, in order to test whether the effectiveness scores of arthroscopic and open surgical methods differ. The ICER was used to compare the treatment methods with cost-effectiveness analysis. The $95 \%$ confidence intervals $(95 \% \mathrm{CI})$ were calculated, with statistical significance set at $\mathrm{P}<0.05$.

\section{RESULTS}

During the research period, 52 patients treated with open surgery and 52 patients treated with arthroscopic surgery were included in the study. Of the patients treated with arthroscopic surgery, $63.46 \%$ were female and 36.54 were male. The ages of the patients in this group ranged between $38-82$ and the mean age was $58.3 .67 .31 \%$ of the patients treated with open surgery were female and $32.69 \%$ were male. The ages of the patients ranged from 37 to 80 years with a mean age of 57.62 years. It was seen that the groups were distributed homogeneously. The mean hospitalization duration was 2.70 days in arthroscopic surgery while it is 3.23 days in open surgery.

Table I. Cost accounts

\begin{tabular}{|c|c|c|c|c|c|c|c|c|c|}
\hline $\begin{array}{l}\text { Types of } \\
\text { Treatment }\end{array}$ & Types of Expenses & Operation & Medicaments & Medical Imaging & $\begin{array}{l}\text { Medical and } \\
\text { Surgical } \\
\text { Materials }\end{array}$ & Hospitalization & Total & $\begin{array}{c}\text { Mann- } \\
\text { Whitney } \\
\text { U }\end{array}$ & p \\
\hline \multirow{3}{*}{ 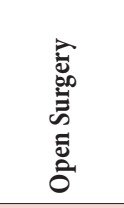 } & Total (TL) & $147,732.61$ & $9,533.17$ & 296.40 & $89,053.22$ & $4,980.00$ & $251,595.40$ & $1,917.00$ & 0.000 \\
\hline & Share in Total Expense (\%) & 58.72 & 3.79 & 0.12 & 35.4 & 1.98 & 100.00 & $2,381.00$ & 0.000 \\
\hline & $\begin{array}{l}\text { Average Cost per Patient } \\
\text { (TL) }\end{array}$ & $2,841.01$ & 183.33 & 5.70 & 1.712 .56 & 95.77 & $4,838.37$ & 764.00 & 0.000 \\
\hline \multirow{3}{*}{ 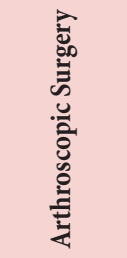 } & Total (TL) & $211,447.21$ & $6,319.89$ & 296.40 & $77,763.68$ & $4,230.00$ & $300,057.18$ & 917.00 & 0.002 \\
\hline & Share in Total Expense (\%) & 70.47 & 2.11 & 0.10 & 25.92 & 1.41 & 100.00 & 440.00 & 0.000 \\
\hline & $\begin{array}{l}\text { Average Cost per Patient } \\
\text { (TL) }\end{array}$ & $4,066.29$ & 121.54 & 5.70 & $1,495.46$ & 81.35 & $5,770.33$ & 808.00 & 0.000 \\
\hline
\end{tabular}

Table I shows the cost findings related to treatment methods. The average cost of treatment with open surgery per patient is 4,838.7 TL (866.22 USD). Surgical intervention with $58.72 \%$ and medical equipment expenses with $35.4 \%$ have the highest share in this cost. The average cost of treatment with arthroscopic surgery per patient is $5,770.33 \mathrm{TL}(1,033.00 \mathrm{USD})$. $70.47 \%$ of this amount is for surgical intervention and $25.92 \%$ of it consists of medical equipment expenses.

Table II. Statistical analysis of open and arthroscopic surgery costs

\begin{tabular}{|c|c|c|c|c|}
\hline Types of cost & $\begin{array}{l}\text { Open Surgery } \\
\text { (TL) }\end{array}$ & $\begin{array}{l}\text { Arthroscopic Surgery } \\
\text { (TL) }\end{array}$ & Mann-Whitney U & p \\
\hline Operation & $2,841.01$ & $4,066.29$ & 138.00 & 0.000 \\
\hline Medicament & 183.33 & 121.54 & $1,826.50$ & 0.002 \\
\hline Medical Imaging & 5.70 & 5.70 & $1,352.00$ & 1.000 \\
\hline Medical and Surgical Materials & $1,712.56$ & $1,495.46$ & $1,941.50$ & 0.000 \\
\hline Hospitalization & 95.77 & 81.35 & $1,690.00$ & 0.019 \\
\hline Average Cost & $4,838.37$ & $5,770.33$ & $1,352.50$ & 0.000 \\
\hline
\end{tabular}


Table II shows statistical analysis of open and arthroscopic surgery costs. Statistically significant difference was found between operation, medication, medical and surgical materials, hospitalization and average cost of those treated with open surgery and those treated with arthroscopic surgery $(\mathrm{p}<0.05)$. However, there was no statistically significant difference between the medical imaging cost of the treatment groups $(\mathrm{p}>0.05)$.

Table III. Results of cost-effectiveness analysis

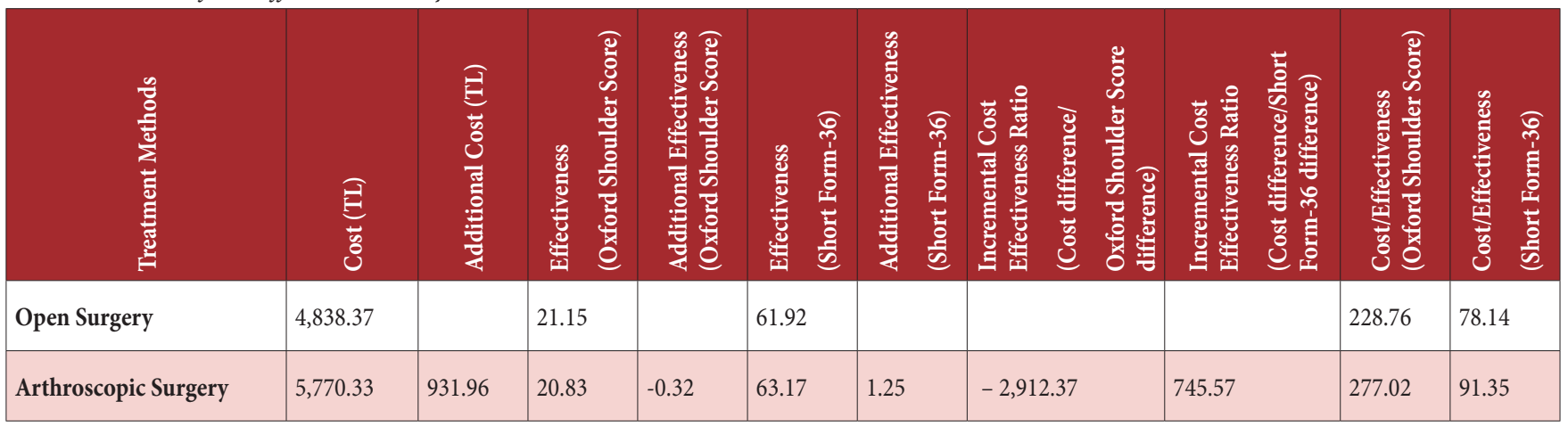

Table III shows the results of the cost-effectiveness analysis. According to the results of the analysis, arthroscopic surgery requires an additional cost of $931.96 \mathrm{TL}$ (166.84 USD) compared to open surgery. No statistically significant difference was found between the Oxford Shoulder Scores of those treated with open surgery and those treated with arthroscopic surgery (MannWhitney $U: 1,468 ; \mathrm{p}>0.05)$. There was no statistically significant relationship between the Short Form 36 General Health Perception sub-scores of patients treated with both surgical methods. (Mann-Whitney U:1,352.5; p>0.05). When the Oxford Shoulder Score values were compared; arthroscopic surgery was found to be 0.32 units less effective than open surgery. When the Short Form 36 General Health Perception sub-scores were evaluated, arthroscopic surgery was found to be 1.25 units more effective than open surgery.

The incremental cost-effectiveness ratio calculated according to the Oxford Shoulder Score was found to be - 2,912.37 TL (521.37 USD). In this case, the cost per additional unit effectiveness by arthroscopic surgery compared to open surgery was - 2,912.37 TL (521.37 USD). The negative value of the ICER indicates that treatment with arthroscopic surgery does not provide additional efficacy. Compared to open surgery, arthroscopic surgery with its high cost and low efficiency was not found to be cost-effective. According to the General Health Perception sub-scores of Short Form 36, ICER was calculated as 745.57 TL (133.47 USD). In this case, an additional unit cost of TL 745.57 is required for another unit improvement in general health status in arthroscopic surgery compared to open surgery. The costs of the treatment methods were divided by the effectiveness scores and the cost of one unit of effectiveness was determined. To gain one unit of effectiveness concerning the Oxford Shoulder Score, an additional cost of 228.76 TL (40.95 USD) is required in open surgical treatment; and in arthroscopic surgery, an additional cost of $277.02 \mathrm{TL}$ (49,60 USD) is required to gain one unit of effectiveness concerning the Oxford Shoulder Score. However, for a one-unit increase in the Short Form 36 General Health
Perception sub-score, an additional cost of 78.14 TL (13,99 USD) arises in open surgery, and an additional cost of $91.35 \mathrm{TL}$ $(16,35$ USD) arises in arthroscopic surgery.

\section{DISCUSSION}

Despite the frequent application of rotator cuff repair, there is no consensus on the best repair technique The appropriate rotator cuff tear surgical treatment is still controversial and patients who undergo surgery have two options as open or arthroscopic treatment. Therefore, focusing on rotator cuff surgery, there has been a significant reduction in failure rate $[16,28]$. Increased treatment costs in health care have led to the necessity of costeffectiveness comparisons between alternative surgical methods. Mather et al., found that surgical and continuous non-operative rotator cuff repair methods are cost effective in all age groups [17]. This finding indicates the curability of each patient. In rotator cuff repair which is very commonly performed, costeffectiveness evaluations were made between various treatment methods. The overall cost-effectiveness of rotator cuff repair [22], surgical and non-surgical methods and cost-effectiveness of alternative surgical methods have been the research question of many studies [28-30]. In this study, open and arthroscopic repair methods were compared in terms of cost and effectiveness. When the studies comparing the cost of open and arthroscopic surgery methods in literature are examined, generally open surgery is found to have a lower cost than arthroscopic surgery $[29,30,17,31]$. In our study also, the cost of open surgery was found to be lower than the cost of arthroscopic surgery. This difference in costs is due to surgical intervention and medical equipment expenses (Table I). Hui et al., concluded in their study that the majority of the cost difference between surgical methods stems from implants and consumables [29]. Narvy et al., reported that the main cost driver factor in rotator cuff repair surgeries is the suture anchor cost [31], Murphy et al., reported that other equipment costs (except anchors) were statistically 
significant requiring $£ 77$ additional cost for arthroscopic surgery procedure [32].

In our study, the Oxford Shoulder Score was used to measure the clinical efficacy of treatment groups, and the Short Form 36 Health Survey Questionnaire, General Health Perception subscale was used to measure general health perception. Dawson et al., have demonstrated a good correlation between Oxford Shoulder Score and Short Form 36 in rotator shoulder tear efficacy measurement [19]. In our study, it was concluded that open surgery had higher value in terms of Oxford Shoulder Score and Short Form 36 General Health Perception sub-scale value was higher in arthroscopic surgery. There was no statistically significant relationship in terms of effectiveness scores of the surgical methods ( $p>0.05$ ). In the literature, treatment methods have been evaluated with various effectiveness measurement tools and some studies do not detect any differences in the effectiveness of treatment methods [32,33,16,17]. Churchill et al., in their study comparing the duration of surgery, determined the time in the mini-open group (103 minutes) to be significantly shorter than the entire arthroscopic group (113 minutes) [34]. In a cost-effectiveness study performed among surgical methods in nineteen hospitals in the United Kingdom, effectiveness scores were measured at 2 weeks, 8 weeks, 8 months, 12 months, and 24 months after surgery. The Oxford Shoulder Score increased in 24 months from 25 to 42.5 in the open group and from 26.3 to 41.7 in the arthroscopic group. However, there was no difference between open repair and arthroscopic repair in terms of clinical efficacy or cost-effectiveness [17].

\section{Limitations}

This study should be reviewed within the framework of certain limitations. The cost-effectiveness assessment of treatment methods was carried out from the perspective of the reimbursement agency. Performing economic assessments also with patients, service providers and community perspectives will provide evidence-based information for more stakeholders. To compare the effectiveness of treatment methods, the scales were administered only once four months after surgery. Evaluating the differences between the measurements by applying the effectiveness scales before surgery and certain periods after surgery will provide more clear results.

\section{Conclusion}

In this study, treatment with arthroscopic surgery was found to be more costly in rotator cuff tear repair compared to open surgery. No statistically significant difference was found between the effectiveness scores of the treatment methods. However, there was statistically significant difference between the costs of the treatment groups. According to the Oxford Shoulder Score which is a clinical efficacy measurement tool, arthroscopic surgery was not found to be cost-effective in terms of shoulder health compared to open surgery. Treatment with arthroscopic surgery was found to be more effective compared to open surgery, although its cost was higher in terms of general health perception according to Short Form 36.

\section{Compliance with Ethical Standards}

Ethical Approval: The study was approved by the Ethical Committee of the Faculty of Health Sciences, Ankara University (approval number: 56786525-050.04.04/7564).

Financial Support: During this study, no financial support was received either from any pharmaceutical company with a direct connection to the research subject, nor from a company that provides or produces medical instruments and materials which may negatively affect the evaluation process of this study.

Conflict of Interest: The authors, their immediate families, and any research foundations with which they are affiliated have not received any financial payments or other benefits from any commercial entity related to the subject of this article.

Author Contributions: M.A.A., N.O., F.I., I.A.: Designed the study, M.A.A, N.O., F.I., I.A.: Gathered the data, M.A.A, N.O., F.I., I.A.: Analyzed the data, M.A.A, N.O., F.I., I.A. : Wrote the initial drafts and M.A.A, N.O., F.I., I.A.: Ensured the accuracy of the data and analysis.

\section{REFERENCES}

[1] Karapınar S, Uruç V, Özden R, Duman İ, Doğramacı Y, Kalac1 A. Clinical radiological outcomes of rotator cuff repair by single-row suture-anchor technique with mini open approach. Dicle Med J 2014; 41: 347-51. doi: 10.5798/ diclemedj.0921.2014.02.0429

[2] Mahiroğulları $M$, İşyar $M$, Çakmak S. Rotator cuff tears. TOTBID Journal 2013;12: 353 - 59. doi: 10.14292/totbid. dergisi.2013.43

[3] Aminzadeh B, Najafi S, Moradi A, Abbasi B, Farrokh D, Emadzadeh M. Evaluation of diagnostic precision of ultrasound for rotator cuff disorders in patients with shoulder pain. Arch Bone Jt Surg 2020;8:689-95. doi:10.22038/ abjs.2020.42894.2166

[4] Kjima H, Minagawa H, Nishi T, Kikuchi K, Shimada Y. Long-term follow-up of cases of Rotator cuff tear treated conservatively. J Shoulder Elb Surg 2012; 2: 491-94. doi:10.1016/j.jse.2011.10.012

[5] Bunker T. Rotator cuff disease. Curr Orthop 2002; 16: 223-33. doi: 10.1054/cuor.2002.0257

[6] Yaradılmış Y, Okkaoğlu M, Şeşen H, Tarğal A, Ateş A, Altay $\mathrm{M}$. There is no difference in between clinical results of fast transosseos repair and double row suture anchor technique for repair of rotator cuff rupture. Bozok Med J 2019; 9 : 1-8. doi: 10.16919/bozoktip.427558

[7] Castagna A, Garofalo R, Maman E, Gray A, Brooks E. Comparative cost-effectiveness analysis of the subacromial spacer for irreparable and massive rotator cuff tears. Int Orthop 2019; 43: 395-403. doi:10.1007/s00264.018.4065-X

[8] First 100 Hospitals in Each Branch 2017 January-October Policlinic, Hospitalization, Intensive Care and Emergency Service Statistics. https://dosyahastane.saglik.gov.tr/ Eklenti/9300,2017-ocak-ekim-donemi-poliklinik-yatis- 
ve-yogun-bakim-ve-acil-servis-verileri-baglaminda-herbransta-ilk-100-hastanepdf.pdf?0 (Access date: 01.11.2019)

[9] Vitale MA, Vitale MG, Zivin JG, Braman JP, Bigliani LU, Flatow EL. Rotator cuff repair: an analysis of utility scores and cost-effectiveness. J Shoulder Elb Surg 2007;16: 181-7. doi: 10.1016/j.jse.2006.06.013

[10] Deprés-Tremblay G, Chevrier A, Snow M, Hurtig MB, Rodeo S, Buschmann MD. Rotator cuff repair: a review of surgical techniques, animal models, and new technologies under development. J Shoulder Elb Surg 2016; 25: 2078-85. doi:10.1016/j.jse.2016.06.009

[11] Wylie JD, Suter, T, Potter, MQ, Granger EK, Tashjian RZ. Mental health has a stronger association with patient-reported shoulder pain and function than tear size in patients with fullthickness rotator cuff tears. J Bone Joint Surg 2016; 98:251-6. doi: 10.2106/JBJS.O.00444

[12] Thangarajah T. Augmentation of rotator cuff tendon-bone healing using demineralised bone matrix and mesenchymal stem cells. 2017; (Unpublished doctoral dissertation) University College London, England.

[13] Itoi E. Rotator cuff tear: physical examination and conservative treatment. J Orthop Sci 2013; 18:,197-204. doi: 10.1007/ s00776.012.0345-2

[14] Weale A, Halabi M, Jones P, White S. Perceptions of outcomes after unicompartmental and total knee replacements. Clin Orthop Relat Res 2001; 382: 143-53. doi:0301-620X/97/11269

[15] Galatz LM, Ball CM, Teefey SA, Middleton WD, Yamaguchi $\mathrm{K}$. The outcome and repair integrity of completely arthroscopically repaired large and massive rotator cuff tears. J Bone Joint Surg 2004; 86:219-24.

[16] Carr C. Cooper CM, Rees J, et. al. Clinical effectiveness and cost-effectivenessof open and arthroscopic rotator cuff repair the UK rotator cuff Surgery (UKUFF) randomised trial. Health Technol Assess 2015; 19: 1-218. doi:10.3310/hta19800

[17] Mather R, Koenig L, Acevedo D, et al. The societal and economic value of rotator cuff repair. J Bone Joint Surg 2013; 95: 1993-2000. doi:10.2106/JBJS.L.01495

[18] Barnes LF, Kim HM, Caldwell JM, et al. Satisfaction, function and repair integrity after arthroscopic versus miniopen rotator cuff repair. J Bone Joint Surg 2017; 99: 2459. doi: 10.1302/0301-620X.99B2.BJJ-2016-0055.R1

[19] Dawson J, Hill G, Fitzpatrick R, Carr A. The benefits of using patient-based methods of assessment. Medium-term results of an observational study of shoulder surgery. J Bone Joint Surg 2001:1: 877-82. doi:0301-620X/01/611316

[20] Grevitt M, Khazim R, Webb J, Mulholland R, Shepperd J. The short form-36 health survey questionnaire in spine surgery. J Bone Joint Surg [Br] 1997;79-B:48-52. doi:10.1302/0301620X.79B1.0790048
[21] McElvany M, McGoldrick E, GA Neradilek, Frederick A. Rotator cuff repair. Int J Sports Med 2014; 43: 491-500. doi:10.1177/036.354.6514529644

[22] Tuğay U, Tuğay N, Gelecek N, Özkan M. Oxford shoulder score: cross-cultural adaptation and validation of the Turkish version. Arch Orthop Trauma Surg 2011; 131: 687-94. doi:10.1007/s00402.010.1242-9

[23] Olley L, Carr A. The use of a patient-based questionnaire (the Oxford Shoulder Score) to assess outcome after rotator cuff repair. Ann R Coll Surg Engl 2008; 90: 326-31. doi:10.1308/003588408X285964

[24] Weale A, Halabi M, Jones P, White S. Perceptions of outcomes after unicompartmental and total knee replacements. Clin Orthop Relat Res 2001; 382: 143-53. doi:0301-620X/97/11269

[25] Oxford Shoulder Score, http://www.orthopaedicscore. com/scorepages/oxford_shoulder_score.html. (access date: 12.11.2019)

[26] Koçyiğit H, Aydemir Ö, Fişek G, Ölmez N, Memiş A. Validity and reliability of Turkish version of SF-36. J Drug Ther 1999; 12: $102-06$.

[27] Iannotti JP, Deutsch A, Green A, et al. Time to failure after rotator cuff repair: a prospective imaging study. $2013 \mathrm{~J}$ Bone Joint Surg 2013;95: 965-71.

[28] Genuario J, Donegan R, Hamman D, et al. The costeffectivenessof single-row compared with double-row arthroscopic rotator cuff repair. J Bone Joint Surg 2012: 94: 1369-77. doi:10.2106/JBJS.J.01876

[29] Hui Y, Teo A, Sharma S, Tan BHM, Kumar V. Immediate costs of mini-open versus arthroscopic rotator cuff repair in an Asian population. J Orthop Surg 2017; 25: 1-6. doi:10.1177/230.949.9016684496

[30] Adla D, Rowsell M, Pandey R. Cost-effectivenessof open versus arthroscopic rotator cuff repair. J Shoulder Elbow Surg 2010; 19: 258-61. doi:10.1016/j.jse.2009.05.004

[31] Narvy SJ, Ahluwalia A, Vangsness CT. Analysis of direct costs of outpatient arthroscopic rotator cuff repair. Am J Orthop (Belle Mead NJ) 2016; 45.1: E7-E11.

[32] Murphy J, Gray A, Cooper C, Cooper D, Ramsay C, Carr A. Costs, quality of life and cost-effectiveness of arthroscopic and open repair for rotator cuff tears: an economic evaluation alongside the UKUFF trial. Bone Joint J 2016;98-B:1648-55. doi: 10.1302/0301-620X.98B12.BJJ-2016-0121.R1.

[33] Carr A, Cooper C, Campbell, et al. Effectiveness of open and arthroscopic rotator cuff repair (UKUFF): a randomised controlled trial. J Bone and Joint Surg 2017; 99: 107-15. doi: 10.1302/0301-620X.99B1.BJJ-2016-0424.R1

[34] Churchill S, Ghoria J. Total cost and operating room time comparison of rotator cuff repair techniques at low, intermediate, and high volume centers: Mini-open versus all-arthroscopic. J Shoulder Elb Surg 2010: 19: 716-21. doi:10.1016/j.jse.2009.10.011 